\title{
Heritability and genetic correlation between the sexes in a songbird sexual ornament
}

\author{
J Potti and D Canal \\ Department of Evolutionary Ecology, Estación Biológica de Doñana-CSIC, Av. Américo Vespucio s/n, Seville, Spain
}

\begin{abstract}
The genetic correlation between the sexes in the expression of secondary sex traits in wild vertebrate populations has attracted very few previous empirical efforts of field researchers. In southern European populations of pied flycatchers, a sexually selected male ornament is also expressed by a proportion of females. Additive genetic variances in ornament size and expression, transmission mechanisms (autosomal vs Z-linkage) and maternal effects are examined by looking at patterns of familial resemblance across three generations. Size of the secondary sex trait has a genetic basis common to both sexes, with estimated heritability being 0.5 under an autosomal model of inheritance. Significant additive genetic variance in males was also confirmed through a crossfostering experiment. Heritability analyses were only partially consistent with previous molecular genetics evidence, as only
\end{abstract}

two out of the three predictions supported Z-linkage and lack of significant mother-daughter resemblance could be due to small sample sizes caused by limited female trait expression. Therefore, the evidence was mixed as to the contribution of the $\mathbf{Z}$ chromosome and autosomal genes to trait size. The threshold heritability of trait expression in females was lower, around 0.3, supporting autosomal-based trait expression in females. Environmental (birth date) and parental effects on ornament size mediated by the mother's condition after accounting for maternal and paternal genetic influences are also highlighted. The genetic correlation between the sexes did not differ from one, indicating that selection on the character on either sex entails a correlated response in the opposite sex. Heredity (2011) 106, 945-954; doi:10.1038/hdy.2010.142; published online 17 November 2010

Keywords: Ficedula hypoleuca; maternal effects; sexual dimorphism; sexual selection; threshold traits; Z chromosome

\section{Introduction}

The amount of linkage to the sex chromosomes of secondary sex traits subjected to sexual selection in breeding systems with genetic sex determination $(X X /$ XY or ZZ/WZ; Rice, 1984; Lande, 1987; Fairbairn and Roff, 2006; Moore and Moore, 2006; Qvarnström and Bailey, 2008) is a subject of certain controversy. This debate is important for at least two reasons. First, the genomic location can influence the correlation between sexually selected traits and preferences for those traits (Kirkpatrick and Hall, 2004; Sæther et al., 2007) and thus directly impinges on Fisher's runaway and the good-genes processes of sexual selection (Kirkpatrick and Ryan, 1991; Kirkpatrick and Hall, 2004; Mank et al., 2006). Second, resolution of the controversy also affects estimates on the rate of evolution, which on the basis of the hemizygosity and subsequent smaller effective population size, is predicted to be steeper for $\mathrm{Y} / \mathrm{Z}$ chromosomes than for $\mathrm{X} / \mathrm{W}$ chromosomes and autosomes (Charlesworth et al., 1987; Rice, 1988; Rowe and Houle, 1996; Fitzpatrick, 2004; Kirkpatrick and Hall, 2004; Fairbairn and Roff, 2006; Mank et al., 2007, 2010). Empirical tests of these ideas have usually approached the issue from comparative perspectives or inferences from reciprocal crosses (Reinhold, 1998;

Correspondence: Dr J Potti, Department of Evolutionary Ecology, Estación Biológica de Doñana-CSIC, Av. Américo Vespucio s/n, Seville 41092, Spain.

E-mail: jpotti@ebd.csic.es

Received 16 September 2010; accepted 14 October 2010; published online 17 November 2010
Mank et al., 2006), genomic scans (Fitzpatrick, 2004; Ellegren et al., 2007; Itoh et al., 2007) or, in birds, wherein males are the homogametic ( $Z Z$ ) and females the heterogametic (WZ) sex, mainly in the context of gene flow and introgression in hybrid zones (Sætre et al., 2003; Sæther et al., 2007; Storchová et al., 2009). However, empirical, molecular results have not settled the question whether sexually selected genes are or not preferentially sex linked (Reinhold, 1998; Fitzpatrick, 2004) and the evidence from natural scenarios is even more limited. Using single-nucleotide polymorphisms, Sætre et al. (2003) concluded that male plumage characteristics, including a white patch in the male forehead, were probably linked to the $\mathrm{Z}$ chromosome in the complex of hybridising European black-and-white flycatchers (pied flycatcher Ficedula hypoleuca and collared flycatcher F. albicollis). This is an important result obtained in species that have become favourite models in sexual selection studies, one that is customarily cited in the literature on speciation and evolution of sex traits as one of the few rendering evidence for $Z(X)$-linked sex traits (Kirkpatrick and Hall, 2004; Mank et al., 2007; Qvarnström and Bailey, 2008; Ellegren, 2009; Mank and Ellegren, 2009). However, Sætre et al. (2003) also recognised that their coarse-grained linkage mapping and the co-linearity they noted between autosomal and Z-genotypes could have affected their results. Independent validation or refutation of sex linkage in other populations and biological contexts (for example, in non-hybridising settings) and arrived at through different approaches would thus help to shed light on the possibility of Z-linkage. 
Despite the increasing availability of long-term studies examining (co)variation of sex and life history traits (Merilä and Sheldon, 2001; Poissant et al., 2009) the genetic correlation between the sexes in the expression of secondary sex traits in wild bird populations has attracted very few previous empirical efforts of field researchers, with some exceptions (for example, barn owls, Tyto alba; Roulin and Dijkstra, 2003; barn swallows, Hirundo rustica; Møller, 1993). In Iberian pied flycatcher (F. hypoleuca iberiae) populations a substantial number of breeding females express a white forehead patch (FP) (42\% expressing it at least once in their lifetimes; $N=851$ individuals; J. Potti, unpublished data; Potti, 1993; Potti and Merino, 1996a; Morales et al., 2007) that is displayed by all breeding males. We capitalised on a relatively large data set obtained throughout long-term ( $>20$ years) measurements and experimental cross-fostering to examine the genetic architecture of a secondary sex trait through both the male and female germ lines. We also aimed to test with field data if genetic transmission may occur through linkage to the $\mathrm{Z}$ chromosome, as suggested by the analyses of Sætre et al. (2003). To that end, we used familial data to try to discriminate among alternative modes of inheritance. As half of their genes in autosomes is inherited by birds from either parent, but the single $\mathrm{Z}$ chromosome of WZ females only from their father, heritability analyses made possible by the measurement of the trait in both sexes can test whether ornament size is inherited on autosomes or may be determined by linkage to the $\mathrm{Z}$ chromosome. Under the hypothesis of Z-linkage at least three testable predictions should hold (see also Trivers, 1985; Lynch and Walsh, 1997; Iyengar et al., 2002): (1) females should resemble their fathers, not their mothers, as by being WZ females always receive their $Z$ chromosome from their father (Lande, 1980). Hence, the female (that is, her father's) Z chromosome is lost in the female's daughters but remains in the female's male ( $\mathrm{ZZ})$ offspring and grandoffspring (Figure 1). Simple autosomal inheritance, on the contrary, does not predict sex biases in familial resemblance and thus both males and females should resemble their parents and grandparents of either sex in the size of their FP. (2) Under Z-linkage, male half-sibs sired by the same father should show lower resemblance than those sharing their mother. This is due to the former inheriting, on average, one of their $\mathrm{Z}$ chromosomes from each of their paternal grandparents while all mothersharing sibs share one of their $\mathrm{Z}$ chromosomes with their maternal grandfather. (3) Similarly, males should show higher resemblance to their maternal than their paternal grandfather (Figure 1), as they always bear a $Z$ chromosome from the former while the likelihood of sharing the other $\mathrm{Z}$ chromosome with their paternal grandfather is diluted by a half when assuming complete Z-linkage and no dominance or epistatic interactions (Lynch and Walsh, 1997).

Similar to male collared flycatchers in the Baltic islands (summarised in Qvarnström et al., 2006) there is apparent directional selection in at least some Iberian populations of pied flycatchers favouring large size of this demelanised ornament in both males and females. Males with larger patches are apparently preferred by female pied flycatchers when choosing mates (Potti and Montalvo, 1991a) and females are mainly fertilised by males bearing ornaments larger than those displayed by both their

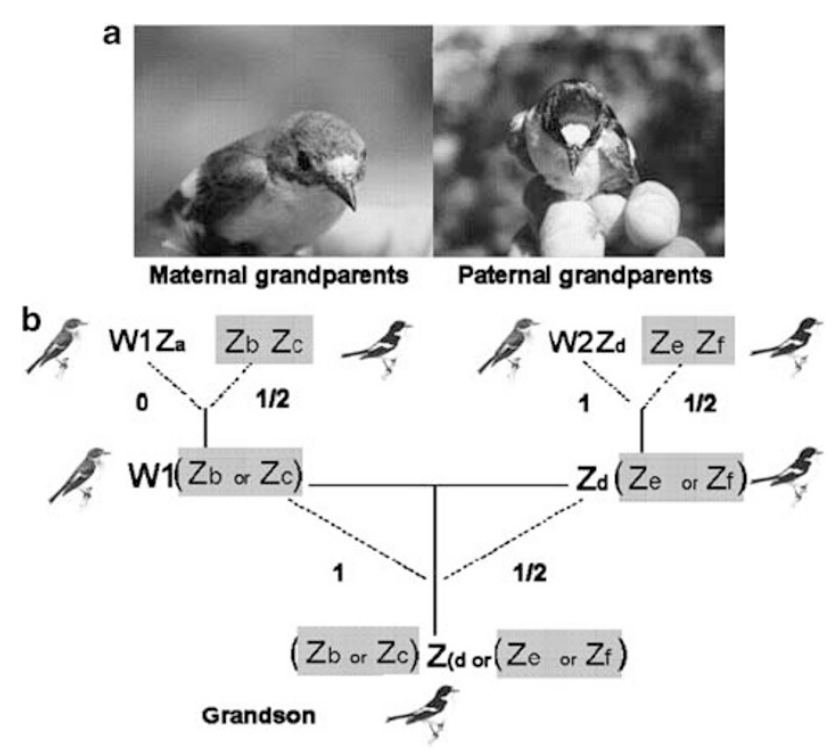

Figure 1 (a) Female (left) and male Iberian pied flycatchers displaying white FP. (b) Schematic relationships of the $Z$ sex chromosome of a male individual (grandson) with those of his mother (left) and father, and maternal and paternal grandparents. Numbers besides dotted lines indicate the probability of sharing the same $\mathrm{Z}$ chromosome across generations.

social mates and neighbours in their extra pair relationships resulting in extra-pair young (D Canal, J Potti and JA Dávila, manuscript under review). Unusually among European populations (Lundberg and Alatalo, 1992; Cramp and Perrins, 1993), some females express with an advancing age FPs as those all males display (Figure 1), although often smaller. Benefits of its expression (absence vs presence) and size in females are less understood, but there is evidence that the ornament signals their age (Potti, 1993; Morales et al., 2007), condition, fecundity and resistance to both endoparasites (trypanosomes; Potti and Merino, 1996a) and nest mite (Dermanyssus) ectoparasites (J Potti and D Canal, manuscript under review). Thus, as suggested for a handful of species (Amundsen, 2000; Griggio et al., 2009), both ornament expression (in females) and size (in both sexes) may act as quality indicators, that is, targets for the establishment of mate preferences in both sexes (Potti and Montalvo, 1991a; Potti and Merino, 1996a; Osorno et al., 2006). The overall scenario of selection apparently favouring large expression of the ornament in males and females is thus of interest in the context of hypotheses stating that the 'vestigial' nature of the expression of sex traits in females has no adaptive utility in itself (Darwin, 1874). In nowadays terminology, this is widely stated as being a by-product of the genetic correlation between the sexes (Lande, 1980, 1987; Bonduriansky and Chenoveth, 2009). A large genetic correlation may severely constrain the rate of the independent evolution of sexual dimorphism (Fisher, 1958; Lande, 1980, 1987; Bonduriansky and Chenoveth, 2009, Poissant et al., 2009) as, among others, has been put in evidence for beak colouration in captive zebra finches Taeniopygia guttata (Price and Burley, 1993, 1994; Price, 1996) and for a non-sexual trait (tarsus length) in collared flycatchers in the wild (Merilä et al., 1998). Here, we first ask whether there is evidence for additive genetic 
variance in size of a sexually selected trait being transmitted through both sexes. We examine patterns in trait heritabilities in the wild and the genetic correlation between the sexes as revealed through several familial comparisons across three generations in male and female pied flycatchers. Heritability of its limited displaying in females is also estimated to gain insight into the trait genetic architecture. As a test of the validity of field results for the male sex, wherein expression is universal in all populations, we use experimental cross-fostering of individuals to assess whether genotype-environment correlation biases our field-derived estimates (Merilä and Sheldon, 2001). We also examine environmental (hatching date) and maternal effects on ornament size and look for testable evidence discriminating on the most likely modes of genetic transmission, that is, Z-linked vs autosomal inheritance.

\section{Materials and methods}

\section{Field methods}

We studied a population of pied flycatchers breeding in nest boxes in La Hiruela, about $100 \mathrm{~km}$ northeast of Madrid, central Spain, in the breeding seasons from 1987 to 2009 (for example, Potti, 2008). Breeding adults were captured, measured for tarsus length ('size', hereafter; with callipers, to the nearest $0.01 \mathrm{~mm}$ ), weighed (precision $0.1 \mathrm{~g}$ ), marked for individual identification with numbered and colour rings and released. The height and width of the male FP were measured with callipers (to the nearest $0.1 \mathrm{~mm}$ ) and the area calculated as FP height $\times$ FP width. Data on FP dimensions could only be taken in a fraction of females (see above). When present, FP length and breadth were measured and the area calculated as for males. Measurements of female FP size were only available from 1993 onward. Many of the breeding adults were born in our nestboxes, wherein they had been marked with a metal ring, and measured and weighed (as for adults) at day 13 of nestling age (Potti and Merino, 1994).

\section{Heritability estimates of character size and expression}

Narrow-sense heritability $\left(h^{2}\right)$ estimates of ornament size assuming autosomal inheritance are presented as a null model to compare with the fulfilment of assumptions should Z-linked transmission be occurring (Falconer and Mackay, 1996; Lynch and Walsh, 1997). Heritabilities were calculated separately through the mother and father for male and female offspring from same-sex offspring means of FP size regressed on one parent ( $h^{2}=2 b$, where $b$ is the regression coefficient). As means and variances of FP differed between the sexes (below) it was first necessary to transform data, which we made by standardising FP values within each sex (zero mean, unit variance; see below).

Analyses of phenotypic resemblance with the grandparent generation $\left(h^{2}=4 b\right.$, when assuming autosomal inheritance) could only be made with males because of small sample sizes of females expressing FP because of age dependency in its first appearance (Potti, 1993). We controlled for the assortative mating with respect to FP size that was earlier reported (Potti and Merino, 1996a) and can bias single-parent, full-sib and offspring-grand- parent heritability estimates (Falconer and MacKay, 1996). Although the within-pair correlation was not strong in the larger sample here analysed, it was also significant $(R=0.16, N=145, P=0.048)$. We therefore corrected those estimates with the expressions provided by Falconer and MacKay (1996) and Nagylaki (1978). The standard errors (s.e.) of parent-offspring and grandparent-grandoffspring heritability estimates were obtained after doubling or quadrupling, respectively, the s.e. obtained by bootstrapping the samples 10000 times.

Further estimates of heritability of FP size were made by analysing its variance components in male fullbrothers, as well as on paternal and maternal halfbrothers (Becker, 1984; Falconer and MacKay, 1996; Lynch and Walsh, 1997). This only could be made for males as we had data for only six female full-sisters in three families and half-sister data were even sparser. The s.e. for these estimates were also found by bootstrapping the samples 10000 times. Variance components were also used to estimate repeatabilities of FP size between individuals across years (Lynch and Walsh, 1997).

Ornament expression is not universal in females (Potti, 1993) and thus may be treated as a threshold character by assuming its expression depends on an underlying normally distributed continuous variable (Falconer and MacKay, 1996; Lynch and Walsh, 1997). As described by Falconer and MacKay (1996: pp. 300-305), we used the binary data on proportions of females expressing (yes/ no) the ornament across lifetime in the population at large $(360 / 491)$ and in a sample of mothers and daughters $(26 / 44)$ to find out the heritability on the underlying scale and its s.e. by considering female expression trait with two classes and one threshold, using the expression accounting for changes in variances across generations (Falconer and Mackay, 1996, pp. 302; Lynch and Walsh, 1997, pp. 733).

\section{Cross-fostering experiment}

To control for the possibility of genotype-environment correlation influencing familial resemblance in ornament size, we used a sample of males recruiting from a limited data set of cross-fostered nests used for other experiments (Potti et al., 2007). In short, we exchanged in 2006 all eggs in the second day of incubation between matched pairs of nests (distant at least $1 \mathrm{~km}$ apart) of the same ( \pm 1 day) breeding date and clutch size. As a result, all pairs of exchanged nests contained broods reared by unrelated adult birds (which was confirmed by DNA fingerprinting; D Canal et al., unpublished data). Twenty-nine males from cross-fostered nests recruited in the 2007 to 2009 breeding seasons, making possible comparisons of their average ornament size to those of their foster and genetic male parents. Familial data on cross-fostered females and their female parents were too limited to be of any use because of age dependence in female ornament expression ( J Potti and D Canal, manuscript under review).

Genetic and phenotypic correlation between the sexes The intersexual genetic correlation $r_{M F}$ was estimated with the expression $\sqrt{ } h_{F D}^{2} h_{M S}^{2} / h_{M D}^{2} h_{F S}^{2}$, where $h^{2}$ are the bootstrapped heritabilities (10000 bootstrap iterations) calculated from father-daughter $(F D)$, mother-daughter 
$(M D)$, mother-son $(M S)$ and father-son $(F S)$ covariances (Bonduriansky and Rowe, 2005).

The phenotypic correlation was estimated from the correlation among male and female full-sib means of standardised FP size (Bonduriansky and Rowe, 2005). Differences between heritability estimates were tested through analysis of covariance (Lynch and Walsh, 1997).

\section{Statistical methods}

Statistics were computed using SAS 9.1 (SAS Institute 2004), R (R Development Core Team 2005) and Statistica 5.1 (StasoftInc, 1996). For a restricted data set of birds measured as fledglings, we built models to investigate on the ontogenetic (size and weight at fledging age), environmental (hatching date) and parental (body condition, by including standardised parental weight and size as covariates) determinants of the ornament size that individual males and females expressed as breeding adults. Linear mixed models were built with procedure GLIMMIX (with normal distribution and individual cohort as a random factor) accounting for male and female parental genetic influences (covariates). Sex and its interactions were included as factors to account for differential responses (Potti and Merino, 1996b), if any, between males and females to predictors of ornament size. In these tests, selection of the best model was carried out by starting from saturated models and removing one by one the effects farthest from statistical significance, starting from the highest order interactions. All tests are two-tailed.

\section{Results}

Analyses are based on 1395 and 367 different measurements of 821 and 234 individual males and females, respectively, which were averaged when measured two or more years. There was significant across-years repeatability of FP size in both males $(R=0.71$ (s.e. $0.023 ; P<0.0001))$ and females $(R=0.43$ (s.e. 0.077 ; $P<0.0001)$ ). Average FP size of males doubled that of females (respective means ( \pm s.d.): $53.50 \pm 12.75$ and $26.57 \pm 10.30 \mathrm{~mm}^{2}$; Figure 2). Variance was 1.5 times higher in males than in females before transformation $\left(F_{1,1050}=17.13, P<0.0001\right)$.

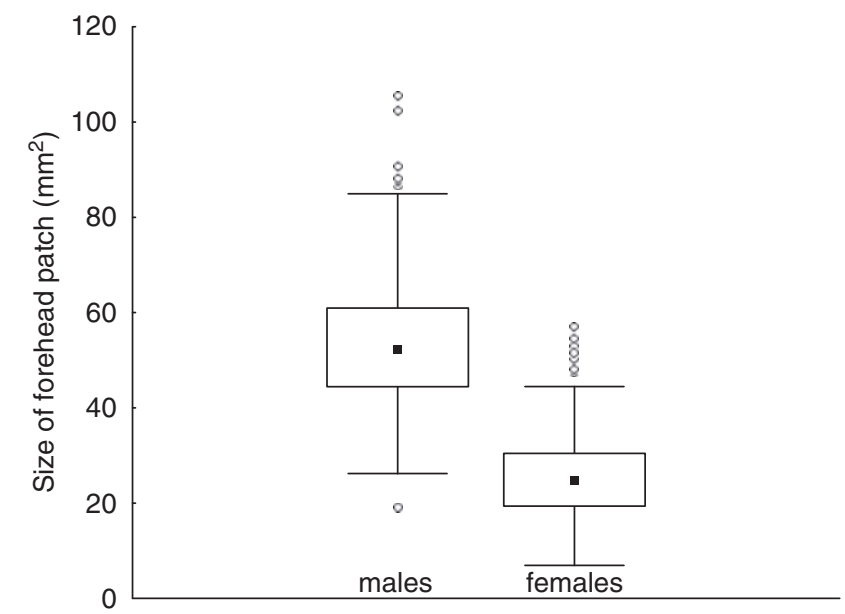

Figure 2 Box plots of variation in size of the ornament in both sexes in Iberian pied flycatchers; shown are medians (solid squares), nonoutlier range (whiskers), 25-75\% quartiles (rectangles) and outliers.
Heritability of ornament expression in females

The heritability in the underlying scale of FP expression from the mother-daughter threshold trait comparison was 0.279 (s.e. 0.054 ), $P<0.001$.

\section{Heritability of ornament size in both sexes}

Parents and offspring of both sexes resembled significantly in FP size in three out of the four comparisons (Table 1, Figure 3). Estimates based on same-sex regressions of offspring on parents were rather consistent, about $50 \%$ of the phenotypic variation in size being explained by genetic differences among parents of either sex (Table 1, Figure 3). Among the parent-offspring comparisons, the mother-son and father-daughter regressions rendered the highest and the lowest heritability, respectively, and the mother-daughter estimate was not statistically different from zero. Heritabilities calculated for daughters (mean 0.44) were lower than those for sons (mean 0.58) and for fathers (0.49) lower than for mothers (0.54; Table 1$)$. However, there were no significant differences among the slopes of regressions in relation to offspring or parental sex in the different analysis of covariance tests (all $P>0.08,108-441$ d.f.). The full- (male) sib comparison rendered a slightly larger value for heritability (Table 1), in accordance with this estimate being presumably inflated by common environmental and dominance genetic variances (Falconer and Mackay, 1996, see, for example, for collared flycatcher; Qvarnström, 1999). Maternal half-sibs were much more similar than paternal half-sibs and both grandparentgrandoffspring estimates of resemblance were similarly high, although the s.e. were large (Table 1).

\section{Heritability of male ornament size: cross-fostering experiment}

The clutch exchange experiment showed that FP size of the males recruiting from cross-fostered clutches did not resemble those of their foster male parents while it very close resembled the FP size of genetic fathers breeding in nests situated far away $\left(h^{2}\right.$ (s.e.) $=1.02$. (0.40), Figure 4). The FP sizes of the genetic and foster fathers were not similar $(r=-0.43, n=18, P=0.073)$.

Table 1 Heritabilities $\left(h^{2}\right)$ with bootstrapped standard errors (s.e.) and associated probabilities $(P)$ of forehead patch size in Iberian pied flycatchers

\begin{tabular}{lccccr}
\hline Familial comparison & $h^{2}$ & s.e. & $\mathrm{P}$ & $h_{z}^{2}$ (coef.) & $\mathrm{N}$ \\
\hline Father-son & 0.56 & 0.12 & 0.0000 & $0.56(1.0)$ & 246 \\
Mother-daughter & 0.46 & 0.36 & 0.1400 & - & 35 \\
Father-daughter & 0.43 & 0.22 & 0.0502 & $0.43(1.0)$ & 76 \\
Mother-son & 0.61 & 0.22 & 0.0068 & $0.31(0.5)$ & 87 \\
Full-brothers & 0.66 & 0.26 & 0.0042 & $0.88(1.3)$ & 40 \\
Paternal half-brothers & 0.43 & 0.48 & 0.1870 & $0.43(1.0)$ & 32 \\
Maternal half-brothers & 1.87 & 0.48 & 0.0003 & $0.93(0.5)$ & 31 \\
Maternal grandfather-grandson & 0.78 & 0.49 & 0.0028 & $0.39(0.5)$ & 57 \\
Paternal grandfather-grandson & 0.74 & 0.35 & 0.0000 & $0.74(1.0)$ & 70
\end{tabular}

The $h^{2}$ values assume autosomal inheritance; $h_{z}^{2}$ values are heritability estimates assuming complete Z-linked inheritance; coef. denote coefficients applied to the familial regressions and analysis of variances (ANOVAs) when assuming complete Z-linked inheritance; $h_{z}^{2}$ is not given for the mother-daughter regression as is predicted to be $0 . N$ is the number of families used in each analysis. 

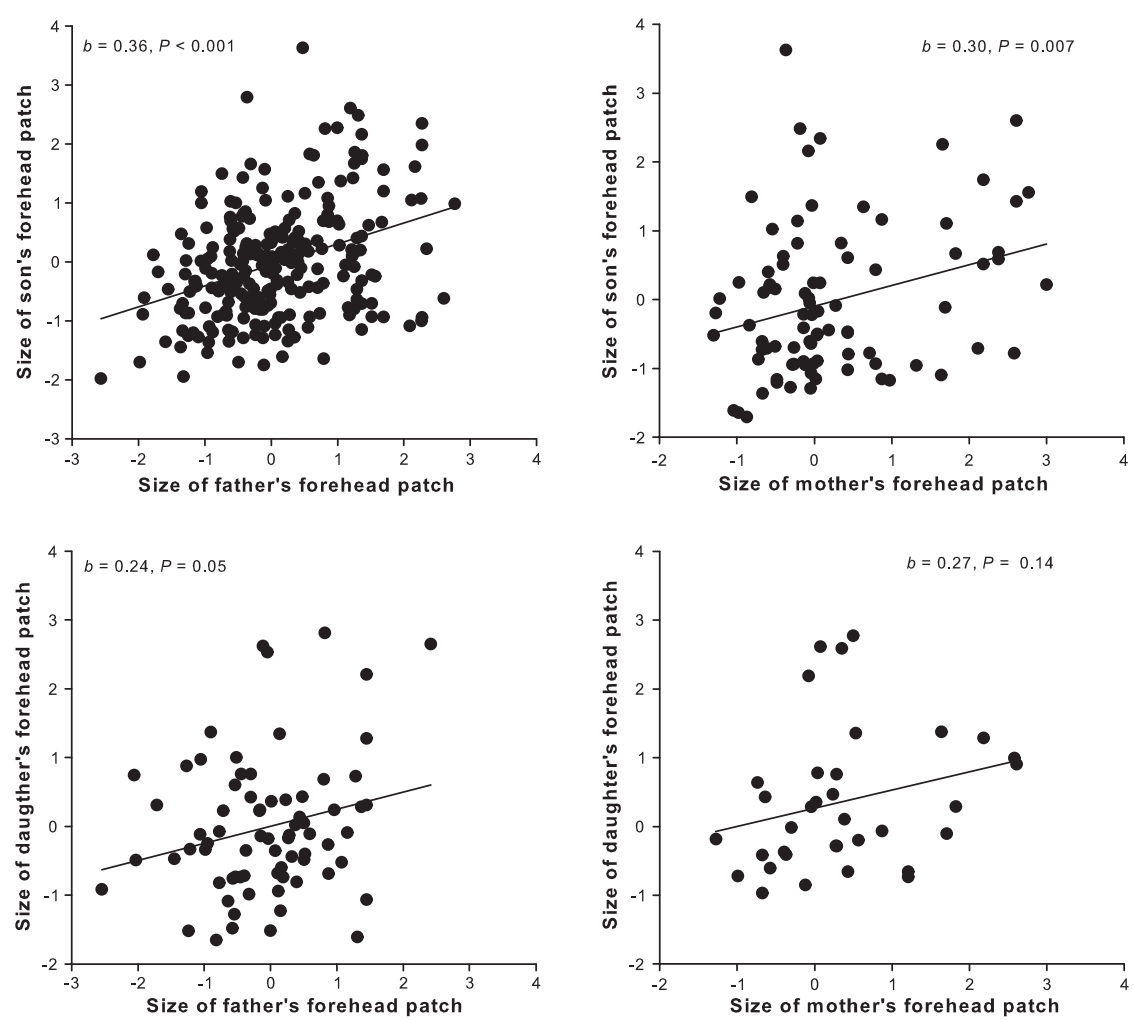

Figure 3 Relationships of standardised size of the ornament in adult offspring of both sexes on those of their fathers and mothers. Lines are fits from linear regressions, with regression coefficients $(b)$ indicated in each case. Note that doubled $b$ coefficients do not equal heritabilities in Table 1 due to the latter being corrected for assortative mating with respect to FP size.
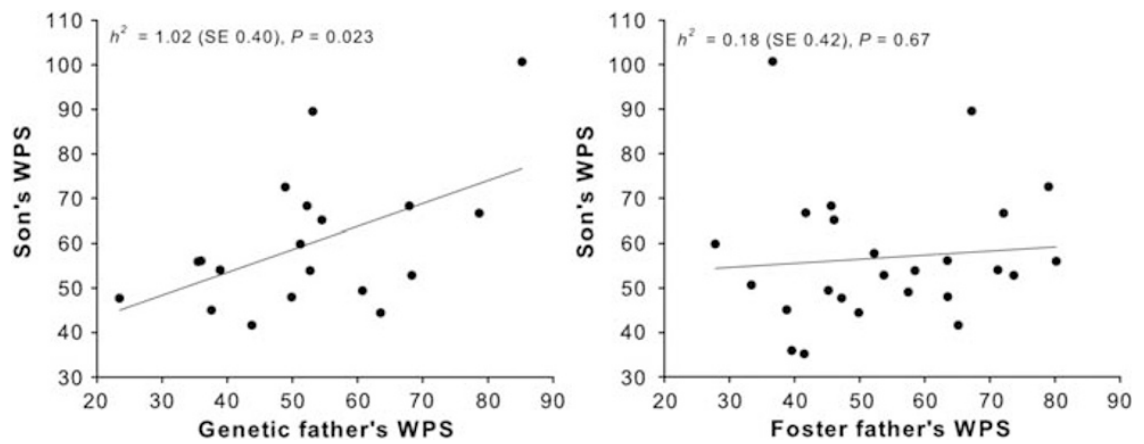

Figure 4 Linear regressions of males' ornament size (WPS, in $\mathrm{mm}^{2}$ ) on those of their foster and genetic male parents. Data from a clutch exchange experiment in 2006. The $h^{2}$ values are doubled regression coefficients.

\section{Z-linked inheritance and maternal effect}

The high heritabilities with both male grandparents and, in particular, the fact that the maternal half-sib estimate greatly exceeds the theoretical maximum for heritability (Table 1) gives support to the hypothesis that genes influencing FP size may not be situated on the autosomes but, rather, on the sex chromosomes (Houde, 1992; Roff, 1997). Under Z-linkage, the coefficient of coancestry for full-brothers becomes $3 / 4$, and that between mothers and daughters should be 0 (see column $h_{z}^{2}$ in Table 1; Trivers, 1985; Lynch and Walsh, 1997). Assuming complete Z-linked inheritance, the maternal grandfather-grandson estimate takes a value similar to those based on parent-offspring comparisons (Table 1). However, the resemblance among maternal half-brothers remained very high (Table 1). This suggests that some of our heritability estimates may be inflated by some type of maternal effect.

There was a positive relationship between the mothers condition while rearing nestlings and size of the ornament her young of both sexes developed at adulthood, after accounting for maternal and paternal genetic influence (Table 2). Further, maternal condition interacted with the size of the male parent ornament, so that individuals grew larger FPs in adulthood when they were sired by fathers bearing large ornaments and mothers in prime condition (Table 2). In addition, there was a significant influence of hatching date on ornament size that was dependent on individual's sex. Females born late in the season grew larger FPs than females born early in the season, while in males FP size did not vary in relation to hatching phenology (Table 2). 
Table 2 Results of the GLIMMIX model explaining variation in standardised forehead patch (FP) size as a function of individual sex, birth date and paternal and maternal FP size and condition while individuals were being cared for by their parents

\begin{tabular}{lcrcc}
\hline Effect & d.f. & Estimate (s.e.) & F & P \\
\hline Intercept & 1,8 & $-0.07(0.21)$ & 0.12 & 0.7313 \\
Sex & 1,60 & $-0.06(0.24)$ & 0.06 & 0.8016 \\
Hatching date & 1,60 & $0.83(0.32)$ & 6.19 & 0.0157 \\
& & & & \\
Sex $\times$ hatching date & & & & \\
$\quad$ Female & 1,60 & $0.79(0.35)$ & 5.12 & 0.0272 \\
$\quad$ Male & 0 & - & - & - \\
Size of father's FP & 1,60 & $0.43(0.10)$ & 17.91 & 0.0000 \\
Size of mother's FP & 1,60 & $0.30(0.11)$ & 8.02 & 0.0063 \\
Mother condition & 1,60 & $0.23(0.12)$ & 3.89 & $0.0531^{\mathrm{a}}$ \\
Size of father's FP $\times$ & 1,60 & $0.23(0.09)$ & 5.84 & 0.0187 \\
mother condition & & & &
\end{tabular}

Only significant explanatory fixed factors and covariates and/or involved in significant interactions in the final model are shown.

aEstimate (s.e.) for mother's condition after removing the father's $\mathrm{FP} \times$ mother condition interaction term $=0.25(0.12), F=4.23,61$ d.f. $P=0.0442$.

\section{Between-sex genetic correlation in ornament size}

The phenotypic between-sex correlation $\left(r_{p}\right)$ in FP size estimated from the female-male, full-sib comparison was $r_{p}$ (s.e.) $=0.41(0.030) ; N=28, P<0.03$. The estimate for the genetic correlation is $r_{M F}=0.87$ (s.e. 0.24 ), which does not differ significantly from $r_{G}=1 \quad(t=-0.54, P>0.50)$ while differing significantly from zero $(t=3.62$, $P<0.001)$. This points out to a common genetic basis for the trait in both sexes, leaving little scope for the independent evolution of ornament size in each sex.

\section{Discussion}

We have shown that a secondary sex trait differentially expressed by all males and over one-third of females in a southern European population of pied flycatchers has a genetic basis common to both sexes. Males resembled both their male and female parents in the standardised size of their ornament, while females only resembled significantly to their fathers. To the best of our knowledge, this is one of the few studies measuring the phenotype of a secondary sexual trait in both parents and progeny as breeding adults and suggesting its genetic transmission through both germ lines in wild populations (review in Poissant et al., 2009). Previously, Roulin et al. (2001 and Roulin and Dijkstra, 2003) capitalised on the fact that both sexes express plumage 'quality' signals at the late nestling stage in barn owls to show that those traits also were genetically correlated between the sexes. As ours, their results implied that selection on one sex for a trait value would indirectly impose selection toward similar values in the other sex and that genes for sex-specific traits can be expressed in the other one because of the between-sex genetic correlation (Lande, 1980, 1987). Although it may be argued that our long-term non-experimental approach could suffer from environmental causes of resemblance (cf. Roulin et al., 2001; Rowe and Day, 2006), our crossfostering experiment unambiguously demonstrated a significant additive genetic component to the trait, at least in males. Limited expression of the ornament and age-dependent expression in female pied flycatchers (Potti, 1993; J Potti and D Canal, paper under review) made unfeasible designing cross-fostering experiments to address the heritability of trait size in this sex. However, even within these sample size constraints, we have been able to suggest for the first time a significant genetic component to threshold sex trait expression in female vertebrates. Our testing of predictions of Z-linked vs autosomal inheritance stemming from Sætre et al. (2003) work gave evidence in support of both models, while discarding independent genetic control of trait size in males and females as recently suggested for the dung beetle Onthophagus sagittarius (Watson and Simmons, 2010). Below we discuss supporting evidence for autosomal and Z-linked inheritance of FP size and its expression in female pied flycatchers.

Before discussing the implications of our findings, we should briefly consider if extra-pair fertilisations, which being relatively frequent in pied flycatchers (Lifjeld et al., 1991; Gelter and Tegelström, 1992; Brün et al., 1996; Moreno et al., 2010), could be biasing our estimates of resemblance. Our data on extra pair fertilisations (D Canal, J Potti and JA Dávila, paper under review) do not allow for a proper estimation of their effect on trait heritability because of a combination of two events with low frequency, that is, recruiting to adult age (which is needed for the ornament being measured; average recruitment rate $=14 \%$, both sexes combined; $N=14$ years and 4536 fledglings; Potti and Montalvo, 1991b, Lehtonen et al., 2009) and being sired by a male other than the social 'father' (average rate of extra-pair paternity about 15\%; D Canal and J Potti, unpublished data). However, as there is no intraspecific brood parasitism in our population, heritabilities calculated with mothers are less prone to this kind of bias than those made with fathers, when mistakenly taking the cuckolded males caring for young in a nest as the genetic father should decrease male-offspring resemblances (Charmantier and Réale, 2005). Further, 'classical' (that is, autosomal) heritabilities did not differ in relation to the sex of parents, suggesting that the unknown rate of misassigned paternity in our long-term database is not biasing the estimates of heritability. In this sense, the absence of differences between both grandparent-grandoffspring estimates of resemblance suggests that the effect of extra-pair paternity is not strong because, if it were, we should expect a lower resemblance for grandoffspring in the paternal line. Thus, we conclude that, irrespective of the mode of inheritance of ornament size, the heritabilities here presented are likely conservative estimates.

The forehead ornament of black-and-white, European Ficedula flycatchers has been proposed as being linked to the $\mathrm{Z}$ chromosome on the basis of evidence based on variation in single-nucleotide polymorphisms (Sætre et al., 2003), although the investigators were careful in recognising that other phenomena, such as the co-linearity they noted between the $\mathrm{Z}$ chromosome and autosomes, could have influenced the patterns they observed. Our evidence was mixed when patterns of inheritance (autosomal vs Z-linked) in ornament size were explored. On one hand, the FP size in females was nearly half the size, on average, of that of males. This is consistent with a model based on Z-linked additive genetic inheritance without dosage compensation in 
which heterogametic WZ females would express a trait half the size, on average, of that of homogametic sex (Ellegren et al., 2007). However, the caveat should be made that the overall degree of dosage compensation, or lack thereof, in the avian sex chromosomes is still unresolved because (1) genomic studies have found large variation, ranging from 0.8 to $>2.4$-fold increases, in levels of expression of Z-linked genes in males relative to females but, (2) differences in the genomic dose of genes usually lead to differences in trait expression that are lower than differences in gene doses, leading to male: female expression ratios being, on average, lower than 2 (Itoh et al., 2007). Therefore, although a doubled male: female ratio in ornament size cannot be taken in isolation as unambiguous support for the hypothesis of Z-linkage, its finding gives some support to hypotheses based on Z-linkage without dosage compensation if accompanied by additional evidence. In this sense, and consistent with $\mathrm{Z}$ linkage, maternal half-sibs showed a large resemblance in ornament size, contrasting with the low one found among paternal half-sibs (Table 1). On the other hand, however, the lack of significant differences between slopes of parent-sons/daughters regressions, and also the fact that grandsons resembled their maternal and paternal grandfathers to a similar degree, gave support to an autosomal model of inheritance. Further, our comparisons showed that patterns of female expression of the ornament are fully consistent with autosomal inheritance.

In conclusion, our results point out that both Z-linked and autosomal inheritance may be involved in trait size and expression. In addition to the co-linearity suggested by Sætre et al., 2003, other processes such as epistatic non-linear interactions between the $\mathrm{Z}$ chromosome and autosomes could be at work. The similar resemblance among grandsons and their maternal and paternal grandfather could be due to epistatic non-linear interactions between the $\mathrm{Z}$ chromosome and autosomes increasing the slope of the paternal grandfather regression, as suggested for sperm length inheritance in dung flies (Ward, 2000). However, the structure of our data does not allow testing this idea and, nevertheless, these estimates had large s.e. Besides genetic factors, maternal effects, one type of environmental contribution with potentially far-reaching consequences to familial resemblance in ornament size (Badyaev, 2002) could be also influencing patterns of trait size inheritance by inflating (for example, Houde, 1992) some of our heritability estimates (Table 1). In fact, the high resemblance among half-sibs of maternal origin also points out to some type of parental effect(s), as individuals in both sexes grew larger ornaments in adulthood when they had been reared by mothers who were themselves in prime condition (Table 2). Maternal effects would likely operate through enhanced development early in the ontogeny that would increase the fitness prospects to offspring reared by parents in good condition and/or breeding in high quality territories (Potti and Merino, 1994; Potti, 1999; Qvarnström, 1999; Badyaev, 2002).

Other explanations to our results cannot be examined with phenotypic data in isolation but could possibly be tested through 'omics' approaches. For instance, pleiotropy would tend to obscure the relationship betweensex linkage and antagonist sexual selection (Fitzpatrick, 2004) usually going on when sexual selection on an ornament in one sex is stronger than natural selection acting against it in the other sex (Mank et al., 2008). Although not common in birds ( $\mathrm{O}^{\prime}$ Neill et al., 2000), genetic mechanisms as genomic imprinting for sex traits could be at work in the chromosomes of Ficedula flycatchers. Speculatively, the small recombinant portion of the $\mathrm{W}$ chromosome (the pseudoautosomal region; Mank and Ellegren, 2007) could also have a role in boosting between-female resemblance. Both the $\mathrm{Z}$ chromosome and autosomes (likely involved in at least trait expression threshold in females) could be jointly implied in the development of differentially expressed secondary sex traits (reviewed in Fairbairn and Roff, 2006), with trait size also possibly being mediated by maternal effects. Further, relatively low (threshold) heritability of trait expression in females suggests that environmental variance may have a large influence on female ornament expression. Only then additive genetic variance for ornament size manifests itself in the female phenotype. Hormonal control of gene expression (McKenna and O'Malley, 2002) could be at work as a correlate of agerelated hormonal changes in females (Gil et al., 2006). Although several physiological mechanisms have been found to control sexual colour dimorphism in birds, male colouration in songbirds is generally dependent on high titres of luteinizing hormone (Kimball and Ligon, 1999). It is expected that expression of male traits in females would be based on male-like modifications of the typical female endocrine environment (Gil et al., 2006).

The genetic correlation between the sexes was near unity, indicating a strong constraint for the evolution of sexual dimorphism in FP size. This could be a case of an initially 'vestigial' (Darwin, 1874; Lande, 1980; reviewed by Bonduriansky and Chenoveth, 2009) trait in females being a product of a genetic correlation between the sexes and favoured in males that has been functionally sequestered to also signal quality in females, thus creating correlated selection between the sexes. The population may not be in equilibrium but rather in the transitional stage envisaged in the models of Lande $(1980,1987)$ of rapid, parallel evolution of male and female characters, which hypothetically, would be followed by a phase of selection acting differentially on each sex, with forces of nearly the same magnitude but of opposite sign. That stage seems not yet reached, maybe because the high between-sex genetic correlation makes the evolution of sexual dimorphism an exceedingly slow process (Lande, 1980, 1987; Bonduriansky and Rowe, 2005; Bonduriansky and Chenoveth, 2009; Poissant et al., 2009). Once exposed to selection, however, all agents of natural and sexual selection on the ornament may not be necessarily coincident in both sexes and/or, given the differences in additive genetic variance (Table $1 ; h_{z}^{2}$ values), would result in similar responses (Lynch and Walsh, 1997; Badyaev, 2002). For instance, if the expression of the ornament in females (which they develop almost always when aged 2 years or older; Potti, 1993) is dependent on hormonal control of gene expression while male displaying is more genetically determined-that is, in the present context, decoupled from genetically programmed or environmentally induced hormonal or genetic switch-offs, selection will act differently on both sexes, if only by being dependent on the interaction between the genetic and environmental components of the hormonal responses across sexes (Dufty et al., 2002). 
Thus, although female showiness could be explained primarily with reference to selective processes directly affecting females (Amundsen 2000) genetic constraints may also be paramount (Roulin and Dijkstra, 2003; this study;reviewed by Poissant et al., 2009).

Our results put forward the intriguing problem if and why, judging from the abundant literature on the genus, female expression of the ornament has been almost altogether suppressed in most northern Eurasian blackand-white flycatcher (F. h. hypoleuca and F. albicollis) populations, in contrast to Iberian ( $F$. $h$. iberiae) ones (Lundberg and Alatalo, 1992; Cramp and Perrins, 1993; cf. Potti, 1993; Morales et al., 2007). Once that genetic and environmental contributions to ornament size in blackand-white European Ficedula species are beginning to be understood (Sheldon et al., 1997; Qvarnström, 1999; Hegyi et al., 2002; Sætre et al., 2003; Sæther et al., 2007; this study), the biggest challenge is now for researchers to explain the within and between-population differences in the degree of inhibition (Williams and Carroll, 2009) of ornament displaying in females, a trait that we show is apparently subject to large environmental/nonadditive genetic variance(s). When optimal trait expression differs between the sexes, between-sex population variation in its degree might cause geographically variable antagonistic selection (Mank et al., 2007), wherein genetic factors spread across populations by giving a reproductive advantage to males while disadvantaging females or vice versa. We need more phenotypic information from central and northern European locations as it seems likely that geographic differences in the degree of expression of apparently sex-limited traits (note we do not necessarily imply sex-linked traits) may contribute significantly to phenotypic differences among populations (Poissant et al., 2009). Differences in both the expression and function of characters shared by males and females can tell us much on sex differences in lifehistory, mate preferences and degree of sexual antagonism within and across populations (Badyaev, 2002; Rowe and Day, 2006). Our knowledge of interactions betweensex chromosomes and autosomes contributing to sexual dimorphisms and antagonistic co-evolution in evolutionary important traits will be furthered on by development of genetic markers and genomic approaches (Wright et al., 2007) being subsequently related to sex and population variation in expression, size and function of those traits.

\section{Conflict of interest}

The authors declare no conflict of interest.

\section{Acknowledgements}

Over the years, JP's work has been funded by the Spanish Ministries of Education, Science and Culture, most recently by projects CGL2006-07481/BOS and CGL2009-10652/BOS. DC was supported by a grant from the Ministerio de Educación y Ciencia (I3PBDP2005). We are most grateful to Roger Jovani, David Serrano, José Luis Tella, Juan José Negro and László Zsolt Garamszegi for valuable input, to Eloy Revilla and Néstor Fernández for guidance with bootstrapping and to AJ Moore for advice on an earlier draft of the paper. We also thank two reviewers for insightful comments.

\section{References}

Amundsen T (2000). Why are female birds ornamented? Trends Ecol Evol 15: 149-155.

Badyaev AV (2002). Growing apart: an ontogenetic perspective on the evolution of sexual size dimorphism. Trends Ecol Evol 17: 369-378.

Becker WA (1984). Manual of Quantitative Genetics. Academic Enterprises: Pullman, Washington, DC.

Bonduriansky R, Rowe L (2005). Intralocus sexual conflict and the genetic architecture of sexually dimorphic traits in Prochyliza xanthostoma (Diptera: Piophilidae). Evolution 59: 1965-1975.

Bonduriansky R, Chenoweth SF (2009). Intralocus sexual conflict. Trends Ecol Evol 24: 280-288.

Brün J, Winkel W, Epplen JT, Lubjuhn T (1996). Parentage analyses in the pied flycatcher (Ficedula hypoleuca) at the western boundary of its central European range. J Orn 137: 435-446.

Charlesworth B, Coyne JA, Barton N (1987). The relative rates of evolution of sex chromosomes and autosomes. Am Nat 130: 113-146.

Charmantier A, Réale D (2005). How do misassigned paternities affect the estimation of heritability in the wild? Mol Ecol 14: 2839-2850.

Cramp S, Perrins CM (1993). Handbook of the Birds of Europe, the Middle East and North Africa Volume VII: Flycatchers to Shrikes. Oxford University Press: Oxford.

Darwin C (1874). Sexual Selection and the Descent of Man. Spanish translation, 1989.El origen del hombre y la selección en relación al sexo EDAF: Madrid.

Dufty Jr AM, Clobert J, Møller AP (2002). Hormones, developmental plasticity and adaptation. Trends Ecol Evol 174: 190-196.

Ellegren H (2009). Genomic evidence for a large-Z effect. Proc $R$ Soc Lond B 276: 361-366.

Ellegren H, Hultin-Rosenberg L, Brunström B, Dencker L, Kultima K, Scholz B (2007). Faced with inequality: chicken do not have a general dosage compensation of sex-linked genes. BMC Biol 5: 40, http://www.biomedcentral.com/ $1741-7007 / 5 / 40$.

Fairbairn DJ, Roff DA (2006). The quantitative genetics of sexual dimorphism: assessing the importance of sex-linkage. Heredity 97: 319-328.

Falconer DS, MacKay TFC (1996). Introduction to Quantitative Genetics. 4th edn. Longmann: London.

Fisher RA (1958). The Genetical Theory of Natural Selection. 2nd edn. Dover: New York.

Fitzpatrick MJ (2004). Pleiotropy and the genomic location of sexually selected genes. Am Nat 163: 800-808.

Gelter HP, Tegelström M (1992). High frequency of extra-pair paternity in Swedish Pied Flycatchers revealed by allozyme electrophoresis and DNA fingerprinting. Behav Ecol Sociobiol 31: $1-7$.

Gil D, Lacroiz A, Potti J (2006). Within-clutch variation in yolk androgens in relation to female expression of a male ornament in pied flycatchers (Ficedula hypoleuca). Ardeola 53: 307-315.

Griggio M, Devigili A, Hoi H, Pilastro A (2009). Female ornamentation and directional male mate preference in the rock sparrow. Behav Ecol 20: 1072-1078.

Hegyi G, Török J, Tóth J (2002). Qualitative population divergence in proximate determination of a sexually selected trait in the collared flycatcher. I Evol Biol 15: 710-719.

Houde AE (1992). Sex-linked heritability of a sexually selected character in a natural population of Poediia reticulata (Pisces: Poeciliidae) (guppies). Heredity 69: 229-235.

Itoh Y, Melamed E, Yang X, Kampf K, Wang S, Yehy N et al. (2007). Dosage compensation is less effective in birds than in mammals. J Biol 6: 2.

Iyengar VK, Reeve HK, Eisner T (2002). Paternal inheritance of a female moth's mating preference. Nature 419: 830-832. 
Kimball RT, Ligon JD (1999). Evolution of avian plumage dichromatism from a proximate perspective. Am Nat 154: 182-193.

Kirkpatrick M, Hall DW (2004). Male-biased mutation, sex linkage, and the rate of adaptive evolution. Evolution 57: 437-440.

Kirkpatrick M, Ryan MJ (1991). The evolution of mating preferences and the paradox of the lek. Nature 350: 33-38.

Lande R (1980). Sexual dimorphism, sexual selection, and adaptation in polygenic characters. Evolution 34: 292-305.

Lande R (1987). Genetic correlations between the sexes in the evolution of sexual dimorphism and mating preferences. In: Bradbury JW, Andersson MB (eds). Sexual Selection: Testing the Alternatives. John Wiley and Sons: Dahlem, pp 83-94.

Lehtonen PK, Laaksonen T, Artemyev AV, Belskii E, Both C, Bureš S et al. (2009). Geographic patterns of genetic differentiation and plumage colour variation are different in the pied flycatcher (Ficedula hypoleuca). Mol Ecol 18: 4463-4476.

Lifjeld JT, Slagsvold T, Lampe HM (1991). Low frequency of extrapair paternity in pied flycatcher revealed by DNA fingerprinting. Behav Ecol Sociobiol 29: 95-101.

Lundberg A, Alatalo RV (1992). The Pied Flycatcher. Poyser: London.

Lynch M, Walsh B (1997). Genetics and Analysis of Quantitative Traits. Sinauer: Sunderland, MA.

Mank JE, Axelsson E, Ellegren H (2007). Fast-X on the Z: rapid evolution of sex-linked genes in birds. Genome Res 17: 618-624.

Mank JE, Ellegren H (2007). Parallel divergence and degradation of the avian W sex chromosome. Trends Ecol Evol 22: 389-391.

Mank JE, Ellegren H (2009). Sex-linkage of sexually antagonistic genes is predicted by female, but not male, effects in birds. Evolution 63: 1464-1472.

Mank JE, Hall DW, Kirkpatrick M, Avise JC (2006). Sex chromosomes and male ornaments: a comparative evaluation in ray-finned fishes. Proc $R$ Soc Lond B 273: 233-236.

Mank JE, Hultin-Rosenberg L, Zwahlen M, Ellegren H (2008). Pleiotropic constraint hampers the resolution of sexual antagonism in vertebrate gene expression. Am Nat 171: 35-43.

Mank JE, Vicoso B, Berlin S, Charlesworth B (2010). Effective population size and the faster-X effect: empirical results and their interpretation. Evolution 64: 663.

McKenna NJ, O'Malley BW (2002). Combinatorial control of gene expression by nuclear receptors and coregulators. Cell 108: $465-474$.

Merilä J, Sheldon BC (2001). Avian quantitative genetics. In: Nolan V, Ketterson E (eds). Current Ornithology, Vol. 16 Kluwer Academic/Plenum Publishers: New York, pp 179-255.

Merilä J, Sheldon BC, Ellegren H (1998). Quantitative genetics of sexual size dimorphism in the collared flycatcher, Ficedula albicollis. Evolution 52: 870-876.

Møller AP (1993). Sexual selection in the barn swallow Hirundo rustica. III Female tail ornaments. Evolution 47: 417-431.

Moore AJ, Moore PJ (2006). Genetics of sexual selection. In: Fox CW, Wolf JB (eds). Evolutionary Genetics Concepts and Case Studies. Oxford University Press: New York, pp 339-349.

Morales J, Moreno J, Merino S, Sanz JJ, Tomás G, Arriero E et al. (2007). Female ornaments in the Pied Flycatcher Ficedula hypoleuca: associations with age, health and reproductive success. Ibis 149: 245-254.

Moreno J, Martínez JG, Morales J, Lobato E, Merino S, Tomás G et al. (2010). Paternity loss in relation to male age, territorial behaviour and stress in the pied flycatcher. Ethology 116: 76-84.

Nagylaki T 1978. The correlation between relatives with assortative mating. Ann Hum Genet 42: 131-137.

O'Neill M, Binder M, Smith C, Andrews J, Reed K, Smith M et al. (2000). ASW: a gene with conserved avian W-linkage and female specific expression in chick embryonic gonad. Dev Genes Evol 210: 243-249.

Osorno JL, Morales J, Moreno J, Merino S, Tomás G, Vásquez R (2006). Evidence for differential maternal allocation to eggs in relation to manipulated male attractiveness in the Pied Flycatcher (Ficedula hypoleuca). J Ornithol 147: 605-611.
Poissant J, Wilson AJ, Coltman DW (2009). Sex-specific genetic variance and the evolution of sexual size dimorphism: a systematic review of cross-sex genetic correlations. Evolution 64: 97-107.

Potti J (1993). A male trait expressed in female pied flycatchers, Ficedula hypoleuca: the white forehead patch. Anim Behav 45: 1245-1247.

Potti J (1999). Maternal effects and the pervasive impact of nestling history on egg size in a passerine bird. Evolution 53: 279-285.

Potti J (2008). Temperature during egg formation and the effect of climate warming on egg size in a small songbird. Acta Oecol 33: 387-393.

Potti J, Blanco G, Lemus JÁ, Canal D (2007). Infectious offspring: how birds acquire and transmit an avian polyomavirus in the wild. PLOS ONE 2: e1276.

Potti J, Merino S (1994). Heritability estimates and maternal effects on tarsus length in pied flycatchers, Ficedula hypoleuca. Oecologia 100: 331-338

Potti J, Merino S (1996a). Decreased levels of blood trypanosome infection correlate with female expression of a male secondary sexual trait: implications for sexual selection. Proc R Soc Lond B 263: 1199-1204.

Potti J, Merino S (1996b). Parasites and the ontogeny of sexual size dimorphism in a passerine bird. Proc R Soc Lond B 263: 9-12.

Potti J, Montalvo S (1991a). Male arrival and female mate choice in pied flycatchers Ficedula hypoleuca in central Spain. Ornis Scand 22: 45-54.

Potti J, Montalvo S (1991b). Return rate, age at first breeding and natal dispersal of Pied Flycatchers Ficedula hypoleuca in central Spain. Ardea 79: 419-428.

Price DK (1996). Sexual selection, selection load and quantitative genetics of zebra finch bill colour. Proc R Soc Lond B 263 217-221.

Price DK, Burley NT (1993). Constraints on the evolution of attractive traits: genetic (co)variance of zebra finch bill colour. Heredity 71: 405-412.

Price DK, Burley NT (1994). Constraints on the evolution of attractive traits: selection in male and female zebra finches. Am Nat 144: 908-934.

Qvarnström A (1999). Genotype-by-environment interactions in the determination of the size of a secondary sexual character in the collared flycatcher (Ficedula albicollis). Evolution 53 1564-1572.

Qvarnström A, Bailey RI (2008). Speciation through evolution of sex-linked genes. Heredity 102: 4-15.

Qvarnström A, Brommer JE, Gustafsson L (2006). Testing the genetics underlying the co-evolution of mate choice and ornament in the wild. Nature 441: 84-86.

$\mathrm{R}$ Development Core Team (2005). R: A Language and Environment for Statistical Computing, Reference Index. R Foundation for Statistical Computing: Vienna. ISBN 3-900051-07-0, URL: http:/ / www.R-project.org.

Reinhold K (1998). Sex linkage among genes controlling sexually selected traits. Behav Ecol Sociobiol 44: 1-7.

Rice WR (1984). Sex-chromosomes and the evolution of sexual dimorphism. Evolution 38: 735-742.

Rice WR (1988). The effect of sex chromosomes on the rate of evolution. Trends Ecol Evol 3: 2-3.

Roff DA (1997). Evolutionary Quantitative Genetics. Chapman and Hall: New York.

Roulin A, Dijkstra C (2003). Genetic and environmental components of variation in eumelanin and phaeomelanin sex traits in the barn owl. Heredity 90: 359-364.

Roulin A, Dijkstra C, Riols C, Ducrest A-L (2001). Female- and male-specific signals of quality in the barn owl. J Evol Biol 14: 255-266.

Rowe L, Day T (2006). Detecting sexual conflict and sexually antagonistic coevolution. Phil Trans R Soc B 361: 277-285.

Rowe L, Houle D (1996). The lek paradox and the capture of genetic variance by condition dependent traits. Proc $R$ Soc Lond B 263: 1415-1421. 
Sætre G-P, Borge T, Lindross K, Haavie J, Sheldon BC, Primmer $C$ et al. (2003). Sex chromosome evolution and speciation in Ficedula flycatchers. Proc R Soc Lond B 270: 53-59.

Sæther SA, Sætre GP, Borge T, Wiley C, Svedin N, Andersson G et al. (2007). Sex chromosome-linked species recognition and evolution of reproductive isolation in flycatchers. Science 318: 95-97.

SAS Institute Inc (2004). SAS/STAT® 9.1. User's Guide. SAS Institute Inc.: Cary.

Sheldon BC, Merilä J, Qvarnström A, Gustafsson L, Ellegren H (1997). Paternal genetic contribution to offspring condition predicted by size of male secondary sexual character. Proc $R$ Soc Lond B 264: 297-302.

Statsoft Inc (1996). Statistica for Windows, Release 5. Computer Program Manual: Tulsa, OK.

Storchová R, Reif J, Nachman MW (2009). Female heterogamety and speciation: reduced introgression of the
$\mathrm{Z}$ chromosome between two species of nightingales. Evolution 64: 456-471.

Trivers R (1985). Social Evolution. Benjamin/Cummings Publ Co: Menlo Park, CA.

Ward PI (2000). Sperm length is heritable and sex-linked in the yellow dung fly (Scathophaga stercoraria). J Zool Lond 251: 349-353.

Watson NL, Simmons LW (2010). Male and female secondary sexual traits show different patterns of quantitative genetic and environmental variation in the horned beetle Onthophagus sagittarius. J Evol Biol 23: 2397-2402.

Williams TM, Carroll SB (2009). Genetic and molecular insights into the development and evolution of sexual dimorphism. Nature Rev 10: 797-804.

Wright D, Kerge S, Brändström H, Schütz K, Kindmark A, Andersson Let al. (2007). The genetic architecture of a female sexual ornament. Evolution 62: 86-98. 